\title{
Article \\ Experimental and Numerical Study of the Laminar Burning Velocity and Pollutant Emissions of the Mixture Gas of Methane and Carbon Dioxide
}

\author{
Yalin Wang ${ }^{1,2, *} \mathbb{D}$, Yu Wang ${ }^{2} \mathbb{C}$, Xueqian Zhang ${ }^{3}$, Guoping Zhou ${ }^{4}$, Beibei Yan ${ }^{1,5}$ and Rob J. M. Bastiaans ${ }^{2}$ \\ 1 School of Environmental Science and Engineering, Tianjin University, Tianjin 300072, China; \\ yanbeibei@tju.edu.cn \\ 2 Departments of Mechanical Engineering, Eindhoven University of Technology, P.O. Box 513, \\ 5600 MB Eindhoven, The Netherlands; y.wang14@tue.nl (Y.W.); r.j.m.bastiaans@tue.nl (R.J.M.B.) \\ 3 Jinan Energy Investment \& Holding Group Co., Ltd., Jinan 250013, China; dreampolice@163.com \\ 4 EBICO (China) Environment Co., Ltd., Wuxi 214125, China; zgp@ebico.com \\ 5 Key Laboratory of Efficient Utilization of Low and Medium Grade Energy, Ministry of Education, School of \\ Mechanical Engineering, Tianjin University, Tianjin 300072, China \\ * Correspondence: wangyalin_rita@163.com
}

check for

updates

Citation: Wang, Y.; Wang, Y.; Zhang, X.; Zhou, G.; Yan, B.; Bastiaans, R.J.M. Experimental and Numerical Study of the Laminar Burning Velocity and Pollutant Emissions of the Mixture Gas of Methane and Carbon Dioxide. Int. J. Environ. Res. Public Health 2022, 19, 2078. https://doi.org/10.3390/ ijerph19042078

Academic Editor: Paul B. Tchounwou

Received: 11 January 2022

Accepted: 9 February 2022

Published: 12 February 2022

Publisher's Note: MDPI stays neutral with regard to jurisdictional claims in published maps and institutional affiliations.

Copyright: (C) 2022 by the authors. Licensee MDPI, Basel, Switzerland. This article is an open access article distributed under the terms and conditions of the Creative Commons Attribution (CC BY) license (https:// creativecommons.org/licenses/by/ $4.0 /)$.

\begin{abstract}
This paper presents the experimental and numerical study of the laminar burning velocity and pollutant emissions of the mixture gas of methane and carbon dioxide. Compared to previous research, a wider range of experimental conditions was realized in this paper: $\mathrm{CO}_{2}$ dilution level up to $60 \%$ (volume fraction) and equivalence ratio of $0.7-1.3$. The burning velocities were measured using the heat flux method. The $\mathrm{CO}$ and $\mathrm{NO}$ emissions after premixed combustion were measured by a gas analyzer placed $20 \mathrm{~cm}$ downstream of the flame. The one-dimensional free flames were simulated using the in-house laminar flame code CHEM1D. Four chemical kinetic mechanisms, GRI-Mech 3.0, San Diego, Konnov, and USC Mech II were used in Chem1D. The results showed that, for laminar burning velocity, the simulation results are all lower than the experimental results. GRI Mech 3.0 showed the best agreement when the $\mathrm{CO}_{2}$ content was below 20\%. USC Mech II showed the best consistency when the $\mathrm{CO}_{2}$ content was between 40 and $60 \%$. For $\mathrm{CO}$ emission, these four mechanisms all showed a small error compared with the experiments. When $\mathrm{CO}_{2}$ content is higher than $40 \%$, the deviation between simulation and experiment becomes bigger. When the $\mathrm{CO}_{2}$ ratio is more than $20 \%$, the proportion of $\mathrm{CO}_{2}$ does not affect $\mathrm{CO}$ emission so much. For NO emission, when the $\mathrm{CO}_{2}$ content is $40 \%$, the results from simulation and experiment showed a good agreement. As the proportion of $\mathrm{CO}_{2}$ increases, the difference in $\mathrm{NO}$ emissions decreases.
\end{abstract}

Keywords: laminar burning velocity measurement; pollutant emissions in premixed combustion; one-dimensional flame simulation

\section{Introduction}

Biogas is one of the renewable fuels that is produced in many different sources, such as sewage sludge, landfills, and organic material [1]. Methane $\left(\mathrm{CH}_{4}\right)$ is the main component of biogas. It is valuable but also harmful to the environment. Biogas can be used for heat, electricity, vehicles, etc., to reduce environmental emissions and the use of fossil fuels. $\mathrm{CH}_{4}$ and carbon dioxide $\left(\mathrm{CO}_{2}\right)$ are the two main components in biogas. $\mathrm{CH}_{4}$ accounts for 55 to $65 \%$ (volume fraction) and $\mathrm{CO}_{2}$ accounts for 35 to $45 \%$ in the biogas from sewage digesters. $\mathrm{CH}_{4}$ accounts for 60 to $70 \%$ and $\mathrm{CO}_{2}$ accounts for 30 to $40 \%$ of the biogas from organic waste. $\mathrm{CH}_{4}$ accounts for 45 to $55 \%$ and $\mathrm{CO}_{2}$ accounts for 30 to $40 \%$ in the biogas from landfills [2].

The usage of biogas will become more and more widely in the future. It is important to research its experimental characterization of fundamental combustion parameters [3]. 
Among a variety of combustion parameters, the laminar burning velocity $\left(\mathrm{S}_{\mathrm{L}}\right)$ is an important requisite to assess flame quenching, flashback, blow-off, and stabilization [4]. The laminar burning velocity is defined as the speed at which an unstretched, adiabatic, and premixed planar flame propagates relative to the unburned mixture [5]. It is a property of fuel-oxidizer mixtures and is a function of initial temperature $(\mathrm{T})$, pressure $(\mathrm{P})$, and equivalence ratio $(\Phi)$. Experimental techniques like the counterflow flame method [6], the heat flux method (HFM) [7], and the spherical flame method [8] can be applied in determining this property. To get the $\mathrm{S}_{\mathrm{L}}$, the one-dimensional and adiabatic flame has to be obtained. For the experiments in this study, the authors use HFM, which was proposed by de Goey et al. [7]. This method stabilizes a stretch less one-dimensional flame without net heat flux and is capable of determining accurate adiabatic laminar burning velocity.

The laminar burning velocity of biogas can also be found in the literature. Cohé et al. [9] used a Bunsen burner to measure the $\mathrm{S}_{\mathrm{L}}$ of the mixture of $\mathrm{CH}_{4}$ and $\mathrm{CO}_{2}$. They got the conclusion that the pressure affected the $\mathrm{S}_{\mathrm{L}}$ much more than the dilution of $\mathrm{CO}_{2}$. Additionally, they used PREMIX code from the program package CHEMKIN-II to simulate biogas under an equivalence ratio of 0.88 , and 0.1 and $0.2 \mathrm{MPa}$ pressure, $300 \mathrm{~K}$ temperature, then they approved that the percentage reduction in $\mathrm{S}_{\mathrm{L}}$ corresponded to the percentage of $\mathrm{CO}_{2}$. The chemical kinetics was GRI-Mech v3.0. Experimentally, Galmiche et al. [10] and Halter et al. [11] used a cylindrical vessel to measure the $S_{L}$ from an initial pressure of 0.1 $\mathrm{MPa}$ and an initial temperature of $393 \mathrm{~K}$ but with up to $20 \% \mathrm{CO}_{2}$ in a stoichiometric mixture with methane linearly, but the decrease of the laminar burning velocity does not show a linear trend. Xie et al. [12] used a constant volume chamber to study the flame instability and flame radiation of $\mathrm{CH}_{4} / \mathrm{CO}_{2} / \mathrm{O}_{2}$ mixtures. Chen et al. [13] carried out research on the effects of diluents on laminar flame speeds of stoichiometric, laminar, and premixed dimethyl ether (DME)/air flames. Qiao et al. [14] used a spherical vessel to measure the $S_{L}$ of premixed methane/air/diluent flames. However, it is difficult to extract the $S_{L}$ from associated conical flames because of curvature effects at the tip and the base. Therefore, de Goey and his colleagues [15] introduced HFM for measuring adiabatic burning velocity and stabilizing flat flames canceling heat fluxes. In recent times, Hermanns [16] used HFM to determine the effect of $\mathrm{H}_{2}$ addition to the $\mathrm{S}_{\mathrm{L}}$ of methane-air mixtures. Konnov and his colleagues [17-20] used a replica of the HFM setup and measured the $\mathrm{S}_{\mathrm{L}}$ of $\mathrm{CH}_{4}, \mathrm{C}_{2} \mathrm{H}_{6}$, and $\mathrm{CH}_{4}-\mathrm{H}_{2}$ mixtures with different dilution ratios of artificial air having $\mathrm{CO}_{2}, \mathrm{~N}_{2}$, or Ar. In contrast again, Clarke et al. [21] used the constant volume technique at zero gravity conditions for the determination of burning velocities of natural gas-like compositions (i.e., methane/diluents-air mixtures). But the stretch corrected data of methane-diluent mixtures do not appear to be available in the literature.

The present work is an experimental and computational investigation into the effect of dilution with $\mathrm{CO}_{2}$ on the adiabatic burning velocity partially along the lines of Nonaka and Pereira [3] but with extended $\mathrm{CO}_{2}$ amounts up to $60 \%$, and additionally $\mathrm{CO}$ and $\mathrm{NO}$ emission. As $\mathrm{NO}$ and $\mathrm{CO}$ are very harmful to the human body, $\mathrm{NO}_{\mathrm{x}}$ is a concern because they contribute to the formation of acid rain, which threatens human health [22,23]. Furthermore, for simulating, we investigate the role of diffusion approximations. The experimental method is HFM. The setup is validated initially by obtaining $\mathrm{S}_{\mathrm{L}}$ values from the measurements of ethane-air mixtures and methane-air mixtures, and also made many comparisons with the literature. We made a closed chamber outside the burner, and installed a probe inside the chamber to measure the $\mathrm{NO}$ and $\mathrm{CO}$ emissions. The computational method is performed by a steady one-dimensional laminar flame code, Chem1D [24]. The reaction mechanisms are four different mechanisms which are GRIMech 3.0 [25], San Diego [26], Konnov [27], and USC Mech II [28], a suitable selection also used by Nonaka and Pereira [3], to predict the $S_{L}$ of the mixtures in and to compare the results from the experiment. 


\section{Materials and Method}

There are two main methods, stationary flame and non-stationary flame methods [29], to obtain the laminar burning velocity. Stationary flames can be established using a burner in which the premixed fuel and oxidant are provided at constant mass flow. Then the flame will establish at the outlet of the burner. Having small experimental deviations, flat flame burners provide the closest approximation to the unstretched flat 1-D flame. Flat flame burners were first used by Powling [30] and then developed by Bosschaart and de Goey [31], amongst others. They reduced the problem of heat transfer and allowed adiabatic burning velocities to be obtained without corrections.

\subsection{Heat Flux Burner}

As already indicated, the HFM is applied for the determination of $S_{L}$ in this paper. Figure 1 shows the heat flux method burner (HFB). There is a burner head on the top and a plenum chamber on the bottom. From the chamber, a uniform flow will be formed. The burner plate is $1 \mathrm{~mm}$ thick. The inlet for the premixed fuel-oxidizer mixture is placed on the bottom of the plenum chamber. The cooling jacket is around the chamber with an inlet water temperature of $25^{\circ} \mathrm{C}$ to keep the inlet gases temperature at a constant level. The heating jacket is located around the burner plate. The inlet water temperature is $85^{\circ} \mathrm{C}$, to keep a stable suitable temperature of the burner plate, having an exothermal flame on top of it, with zero net heat flux by adjusting the mass flow. There are several thermocouples attached to the burner plate to measure the radial temperature of the burner plate.

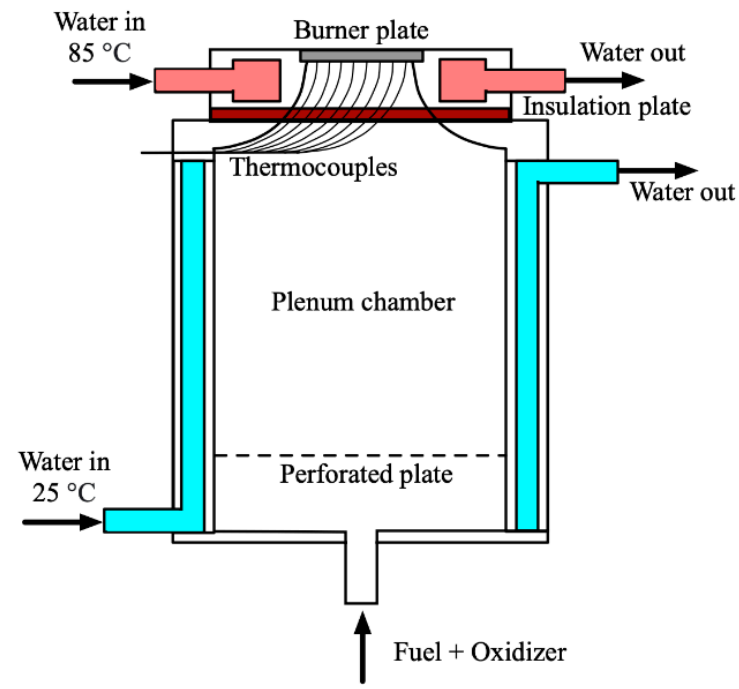

Figure 1. Schematic diagram of the heat flux burner.

\subsection{The Principle of the Experiment}

In HFB's, there is no flame stretch and flow straining. This adiabatic flame condition can be realized by adding the heat from the burner plate to the unburnt gas portion to make up the heat loss from the flame to the burner head [32]. The mechanism is shown in Figure 2. The temperature distribution of the burner plate is as the following equation:

$$
T_{p(r)}=T_{c e n t e r}+C r^{2},
$$

in which $r$ represents radius from the center of the burner plate, $T_{p(r)}$ represents the temperature at different $r, T_{\text {center }}$ represents the temperature at the center of the burner plate and $C$ represents a parabolic coefficient variant related to the heat transfer $[7,31]$. In the complete burner plate, there are several thermocouples placed at different $r$. These thermocouples would show the data of $T_{p(r)}$ and $C$. When the value of $C$ is zero, the 
temperature distribution is flat, then the adiabatic flat flame is obtained. The diameter of each hole is indicated by $\mathrm{d}$ and $\mathrm{s}$ is the center distance between each hole.

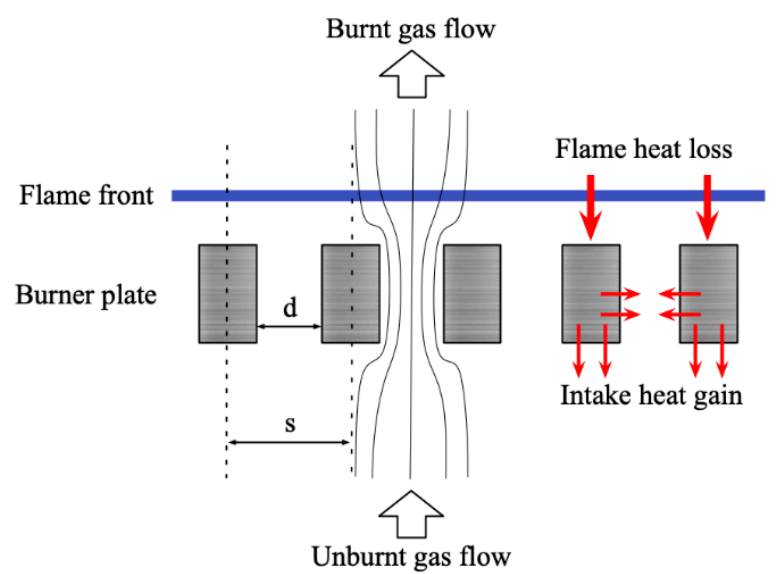

Figure 2. The heat flux compensation mechanism for the one-dimensional adiabatic laminar flame.

\subsection{Experimental Design}

Figure 3 shows the schematic design of the setup used in this study. This HFM setup was built for gaseous fuels at atmospheric pressure. The current burner plate is shown in Figure 4, as follows. The perforation pattern was $0.4 \mathrm{~mm}$ holediameter and $0.51 \mathrm{~mm}$ pitchdistance. The outer diameter is $20 \mathrm{~mm}$; there were 1362 holes totally in this burner plate. The material of the burner plate was brass and the material of the insulation plate was nylon. Several thermocouples were placed flush-mounted in the plate. There was a computer connected to all thermocouples to run Labview for analyzing the data. The types of mass flow controller (MFC) are Bronkhorst FG-201CV-RAD-33-V-DA-000 for $\mathrm{CO}_{2}$, FG-201CV-RAD-33-V-DA-A1V for $\mathrm{CH}_{4}$ and air. The range of pressure for all MFCs were from $0-5$ bar. All MFCs were calibrated with professional equipment and set up before the experiment. The left part in Figure 3 is the gas supply part. The purity of $\mathrm{CO}_{2}$ is $99.995 \%$. The purity of $\mathrm{CH}_{4}$ is $99.5 \%$. The experimental conditions are $1 \mathrm{~atm}$ and $298 \mathrm{~K}$. A gas analyzing probe is located $20 \mathrm{~cm}$ above the HFB. The series of the gas analyzer is MRU VARIO Plus. It can give real-time and long-term monitoring for several emission gases, such as $\mathrm{CO}, \mathrm{CO}_{2}, \mathrm{CH}_{4}, \mathrm{NO}, \mathrm{NO}_{2}, \mathrm{SO}_{2}, \mathrm{H}_{2} \mathrm{~S}, \mathrm{H}_{2}$, etc. This is a portable stack gas emission analyzer for long time measurements of industrial combustion. The outstanding benefits of it are that it is the most suitable method for low $\mathrm{NO}_{\mathrm{x}}$ measurements and other toxic gas emissions measurements. The accuracy of it is 5\% for $\mathrm{NO}$ and $3 \%$ for $\mathrm{CO}$.

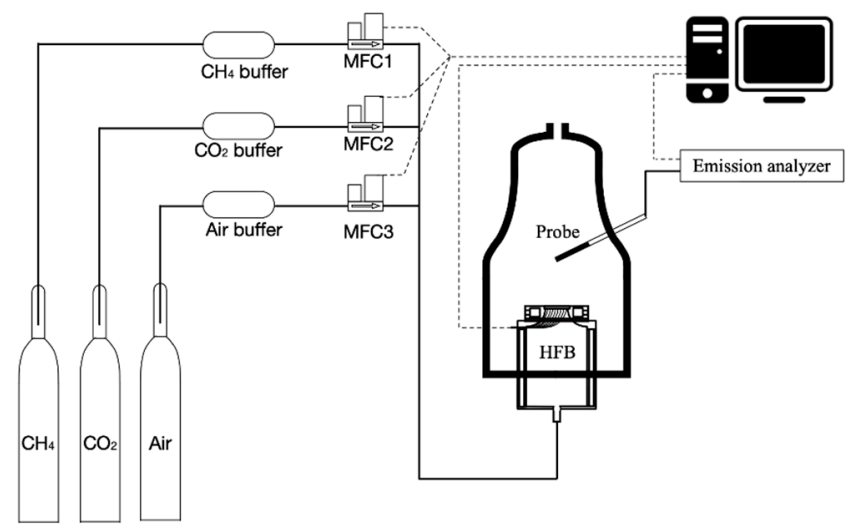

Figure 3. Schematic design of the setup. 


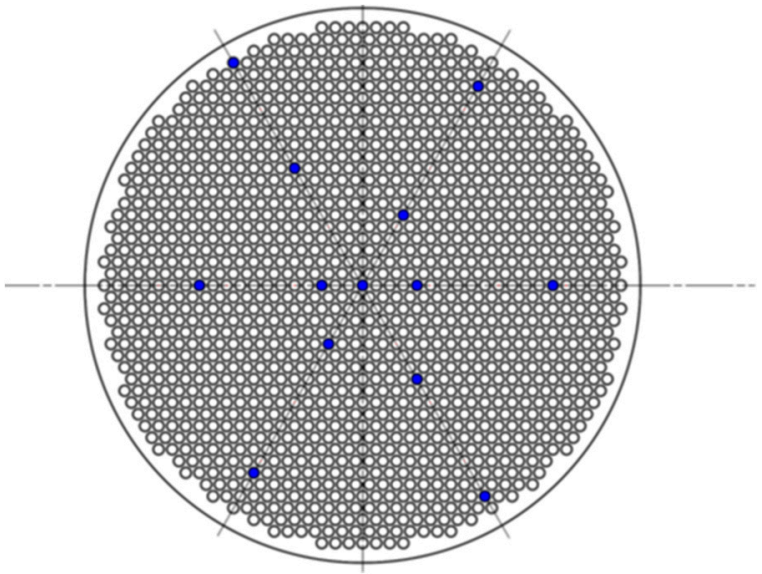

(a)

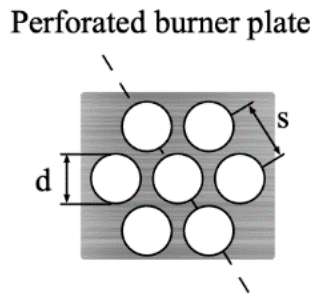

(b)

Figure 4. Burner plate. (a) The perforated burner plate with 13 thermocouples (blue dots) installed on it, (b) the holediameter and the pitchdistance.

\subsection{Error Analysis}

Alekseev et al. [33] identified the uncertainties in laminar burning velocity in the HFM setup and the HFB method in the experiment. The main reason for uncertainties is the uncertain value of the parabolic coefficient $C$. The factors include the temperature of the burner plate, the mass flow, the control from the MFC, and the inlet gas temperature. The value of $C$ can be obtained from linear regression of the temperature data over the burner plate. The uncertainty $\sigma_{C}$ can be shown as the following equation:

$$
\left(\frac{\frac{1}{N-2} \sum_{i}\left(T_{i}-C \cdot\left(r^{2}\right)_{i}-T_{\text {center }}\right)^{2}}{\sum_{i}\left(\left(r^{2}\right)_{i}-\left(\overline{r^{2}}\right)\right)^{2}}\right)^{\frac{1}{2}}
$$

In Equation (2), $N$ represents the number of thermocouples, $T_{i}$ is the thermocouple reading at the distance of $r$ and $\left(\overline{r^{2}}\right)$ is the mean of the squared $r$.

\subsection{One-Dimensional Flame Simulation}

The one-dimensional free flames were simulated using the in-house laminar flame code CHEM1D [24] to get solutions, including $S_{L}$. CHEM1D solves a set of equations describing the conservation of mass, momentum, energy, and species for chemically reacting flow using an exponential finite-volume discretization in space [4]. Non-linear differential equations were solved with a fully implicit, modified Newton method along with an option to invoke several transport models, including the complex one. An adaptive gridding procedure was also achieved to increase accuracy in the flame front by placing almost $80 \%$ of the grid points in the area with the largest gradients [16]. Basic thermodynamic data were from Burcat and Ruscic [34]. CHEM1D can calculate not only with a simple one-step reaction mechanism but can also run with complex chemistry. Many kinetic mechanisms have been developed, such as Li et al. [35], Burke et al. [36], Kéromnès et al. [37], and GRI Mech 3.0 [25]. The users can use different mechanisms in Chem1D directly without editing. GRI-Mech 3.0 is an updated mechanism derived to simulate natural gas combustion, including NO formation and reburn chemistry. This method is a widely recognized good mechanism for natural gas in much research, e.g., [38-40]. The pressure range for GRI Mech 3.0 is wide from 0.1 to $10 \mathrm{~atm}$. The main gas for San Diego [26] is hydrocarbons. San Diego can use the minimum number of reactions and species to explain the phenomenon to increase accuracy compared with GRI 3.0. USC Mech II is a detailed kinetic mechanism specialized for a large number of combustion processes from $\mathrm{C} 0$ to $\mathrm{C} 4$ with 111 species 
in 784 reversible reactions [28]. The main gas used for USC Mech II is syngas which is consistent with $\mathrm{H}_{2}$ and $\mathrm{CO}$ in the high-temperature oxidation process [41]. The Konnov mechanism is very exact chemistry for low temperature and radical effects. The current version of the mechanism (Release 0.5 ) consists of 1200 reactions among 127 species [27].

\section{Results and Discussion}

\subsection{Effect of $\mathrm{CO}_{2}$ Addition on Laminar Flame Velocity}

The variation principle of laminar burning velocity with the addition of $\mathrm{CO}_{2}$ is shown in Figure 5 below. The laminar burning velocity all show a linear downward trend under different equivalence ratios. When the addition ratio of $\mathrm{CO}_{2}$ is from 40 to $60 \%$, the decreasing rate of $\mathrm{S}_{\mathrm{L}}$ becomes larger. When the addition ratio of $\mathrm{CO}_{2}$ is from 20 to $40 \%$, the decreasing rate of $S_{L}$ becomes smaller. Figure $5 b$ shows a comparison with the data from the literature.

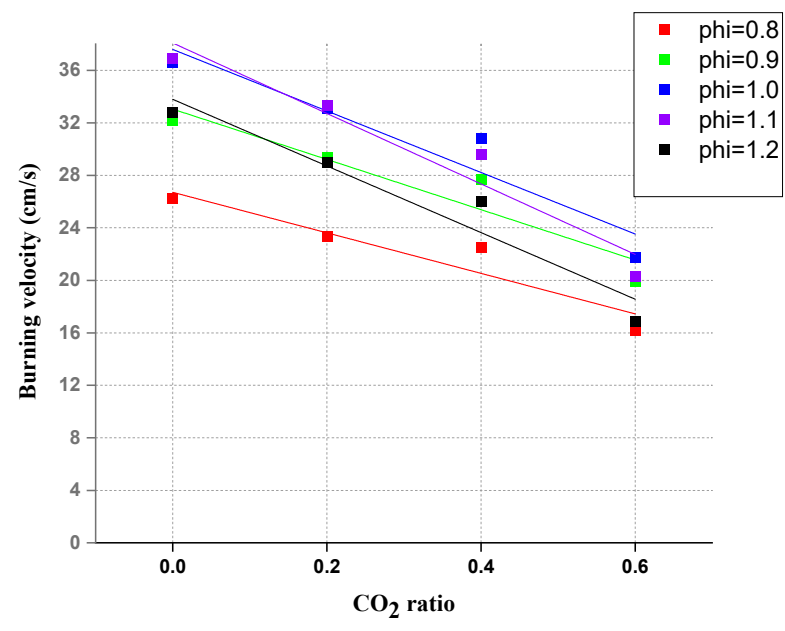

(a)

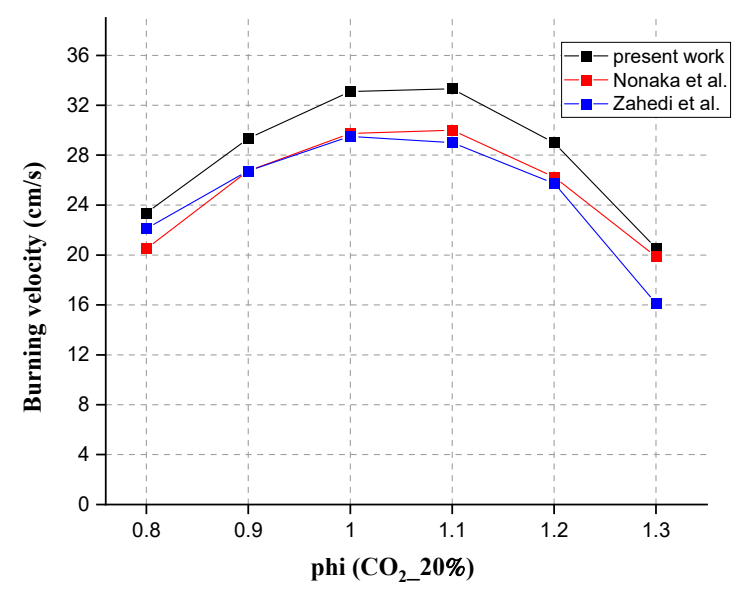

(b)

Figure 5. (a) Measured data: laminar burning velocity with the addition of $\mathrm{CO}_{2}$, (b) adiabatic laminar burning velocities with literature data $[3,42]$.

\subsection{Comparison between Experimental and Simulation Results Using Different Mechanisms}

There were four mechanisms chosen in this study, which are GRI-Mech 3.0 [25], San Diego [26], Konnov [27], and USC Mech II [28]. Because they are the common mechanisms for gas simulations, like $\mathrm{H}_{2}, \mathrm{CH}_{4}$ etc. For the $\mathrm{CO}_{2} / \mathrm{CH}_{4}$ mixtures, the compositions investigated are: $0 / 100,20 / 80,40 / 60$, and $60 / 40 \% / \%$ (all by volume fraction). The range of equivalent ratio $\Phi$ is from 0.7 to 1.3. The pressure is $1 \mathrm{~atm}$ and the temperature is 298 $\mathrm{K}$. Both burning velocities and $\mathrm{CO}$ and $\mathrm{NO}$ emissions were reported. The results for $\mathrm{CO}$ emissions and $\mathrm{NO}$ emissions were taken at a downstream position of $20 \mathrm{~cm}$, the latter as measured in the accompanying experiments.

From Figure 6, it can be observed that all mechanisms involved showed the same tendency. The simulation results were all lower than the experimental results. GRI Mech 3.0 showed the best agreement when the $\mathrm{CO}_{2}$ content was below $20 \%$. When $\mathrm{CO}_{2}$ accounted lower than 20\%, the ranking of accuracy among all four mechanisms was GRI-Mech $3.0>$ USC Mech II > Konnov > San Diego. When $\mathrm{CO}_{2}$ accounted for 40 and $60 \%$, the ranking of accuracy interchanged between the first two. All in all, GRI-Mech 3.0 was the best choice for $\mathrm{S}_{\mathrm{L}}$ simulation of mixed gas in Chem1D when $\mathrm{CO}_{2}$ accounted for lower than $20 \%$. USC Mech II was a good mechanism when the mixed gas had a higher concentration $(>40 \%)$ of $\mathrm{CO}_{2}$. 


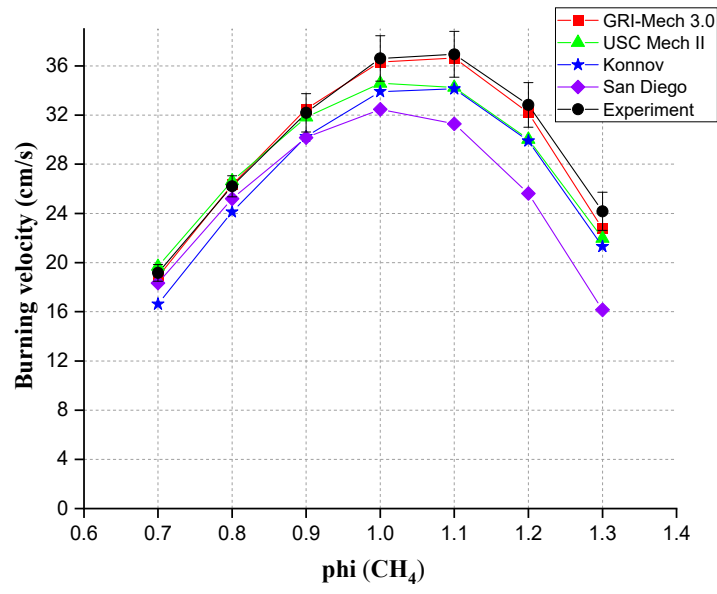

(a)

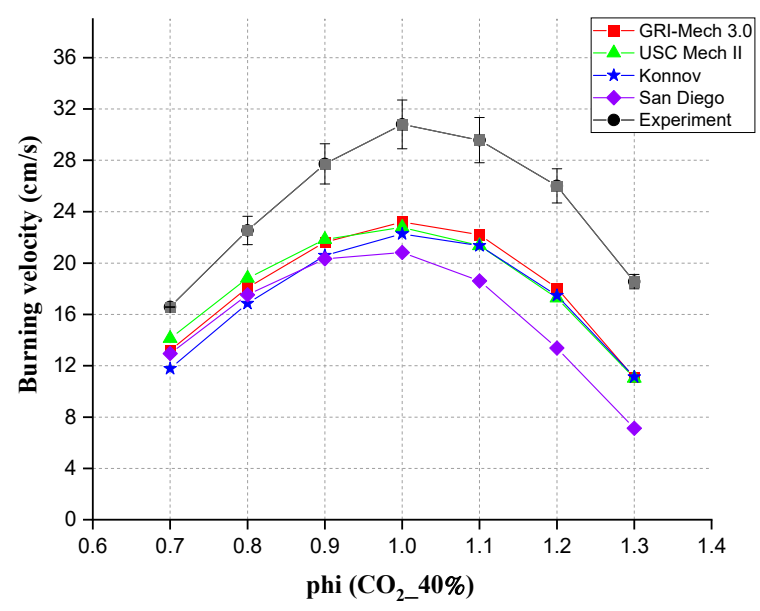

(c)

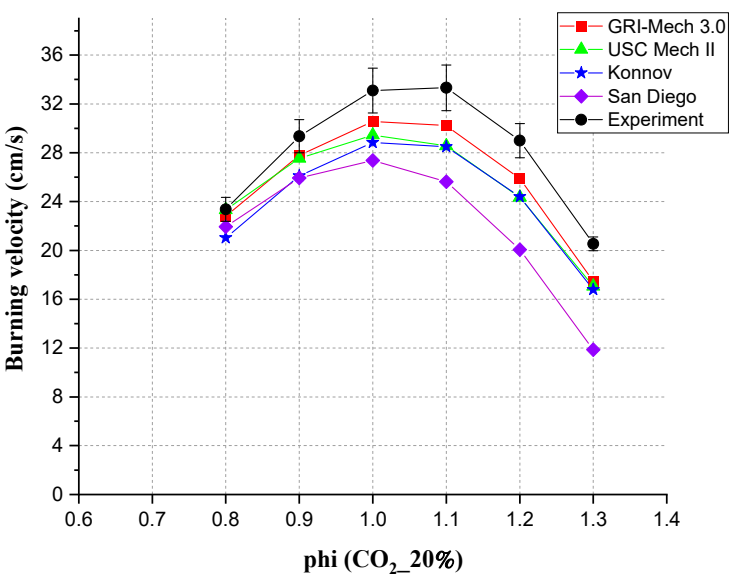

(b)

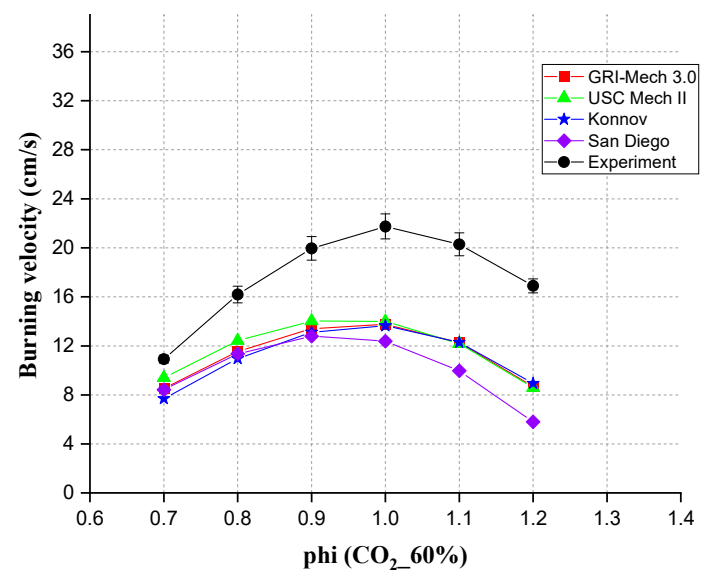

(d)

Figure 6. Comparison between simulation values (different simulation mechanisms) and experimental value for different mixtures, (a) $\mathrm{CH}_{4}$, (b) $20 \% \mathrm{CO}_{2}$, (c) $40 \% \mathrm{CO}_{2}$, (d) $60 \% \mathrm{CO}_{2}$.

When the gas was $\mathrm{CH}_{4}$ and when the $\mathrm{CO}_{2}$ accounted for $20 \%$, the highest values of $\mathrm{S}_{\mathrm{L}}$ appeared at $\Phi=1.1$ in the experiments. In other proportions of $\mathrm{CO}_{2}$ in this experiment, the highest values of $S_{L}$ were found at $\Phi=1.0$; therefore, the highest $S_{L}$ mainly appeared in the interval from 1 to 1.1 in the experiment. But the Chem1D simulation results showed the highest $\mathrm{S}_{\mathrm{L}}$ at $\Phi=1.1$ for $\mathrm{CH}_{4}$ for GRI 3.0 and Konnov. For other ratios of mixed gases, simulations with different mechanisms did not give a synchronous prediction for the peak value of $S_{L}$. The peak value of $S_{L}$ for other mixed gases all appeared at $\Phi=1.0$ from Chem1D simulation results, so the experiments presented the change of $S_{L}$ in a more trustworthy manner.

\subsection{Comparison of Experimental and Simulated Values of Different Concentrations of $\mathrm{CO}_{2}$}

From both simulation and experiment, the changing trends of $\mathrm{S}_{\mathrm{L}}$ showed a consistent pattern. In Figure 7, the behavior was shown for different mixtures in experiments and for simulations with GRI 3.0. When the range of $\Phi$ was between 0.7 and 1.0, as $\Phi$ increased, $\mathrm{S}_{\mathrm{L}}$ showed an increasing trend as well. When the range of $\Phi$ was between 1.0 and 1.3, as $\Phi$ increased, $\mathrm{S}_{\mathrm{L}}$ showed a decreasing trend. The authors used the mechanism of GRI Mech 3.0 to show how the $\mathrm{S}_{\mathrm{L}}$ changed with the concentration of $\mathrm{CO}_{2}$ in the simulation. As the concentration of $\mathrm{CO}_{2}$ increased every $10 \%$, under the same $\Phi$, the $\mathrm{S}_{\mathrm{L}}$ also showed a corresponding regular decrease. From the experimental results, under the same $\Phi$, the $S_{L}$ decreased as well. 


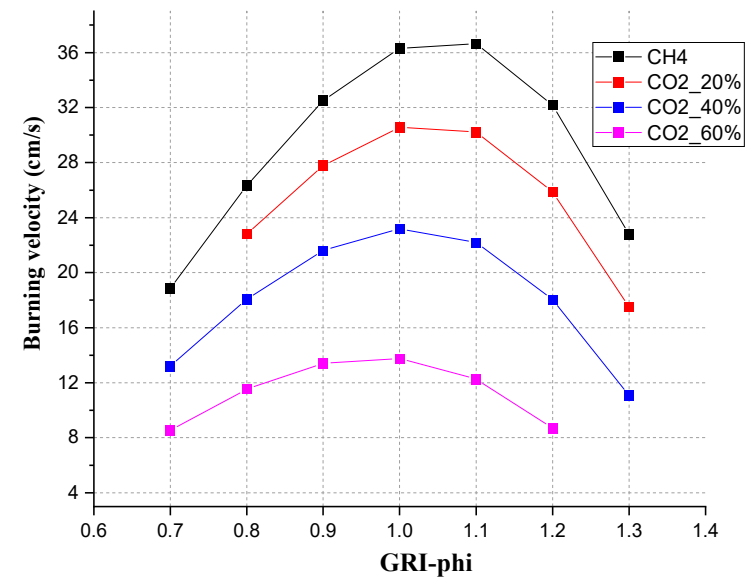

(a)

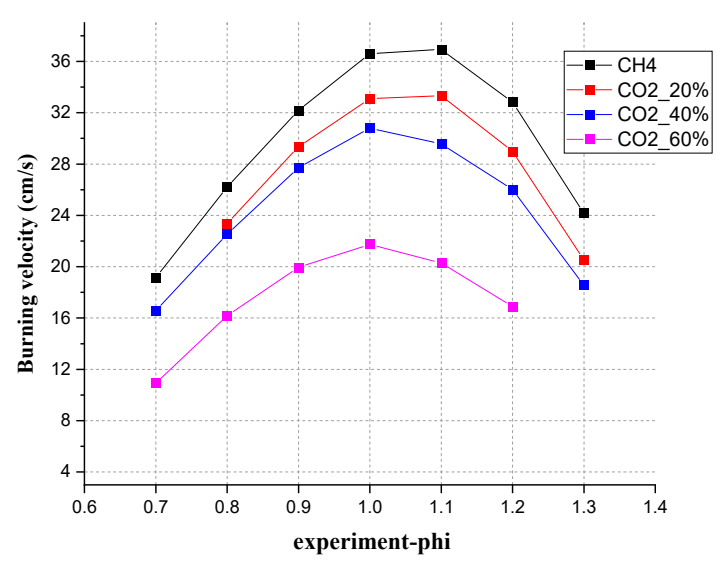

(b)

Figure 7. The burning velocity for different $\mathrm{CO}_{2}$ compositions (a) from the experiment, and (b) from simulations with GRI 3.0.

\subsection{The Emission of CO, Simulation and Experimental Results at $20 \mathrm{~cm}$ Downstream}

From Figure 8, for the CO emissions at the location of the measurement probe, the results from the four kinetic mechanisms used in Chem1D showed very little deviation from each other, though a small deviation with experiment can be observed. Under every ratio of $\mathrm{CO}_{2}$ content, the $\mathrm{CO}$ emissions increase as $\Phi$ increases. For the pure $\mathrm{CH}_{4}$ and mixed gas with a $\mathrm{CO}_{2}$ ratio below $40 \%$, the experimental results showed good consistency with the simulation results. At lean conditions, the $\mathrm{CO}$ emissions are almost zero as expected. Then, in rich conditions, when there is insufficient $\mathrm{O}_{2}$ for complete combustion, it increased rapidly after $\Phi=1.0$. After $\Phi=1.0$, the experimental results showed a higher $\mathrm{CO}$ emission than simulation. Like the Figure $8 \mathrm{~d}$ of $\mathrm{CO}_{2}=60 \%$. This is consistent with the theoretical principle. More $\mathrm{CO}$ will emerge under the rich $\mathrm{CO}_{2}$ situation. The simulation results all showed a continuous acceleration of growth rate from $\Phi=1.0$ to $\Phi=1.3$. From the experiment, when $\mathrm{CO}_{2}$ accounts for lower than $40 \%$, the increasing slope of $\mathrm{CO}$ emission was first steep from $\Phi=1.0$ to $\Phi=1.2$, then became slow from $\Phi=1.2$ to $\Phi=1.3$.

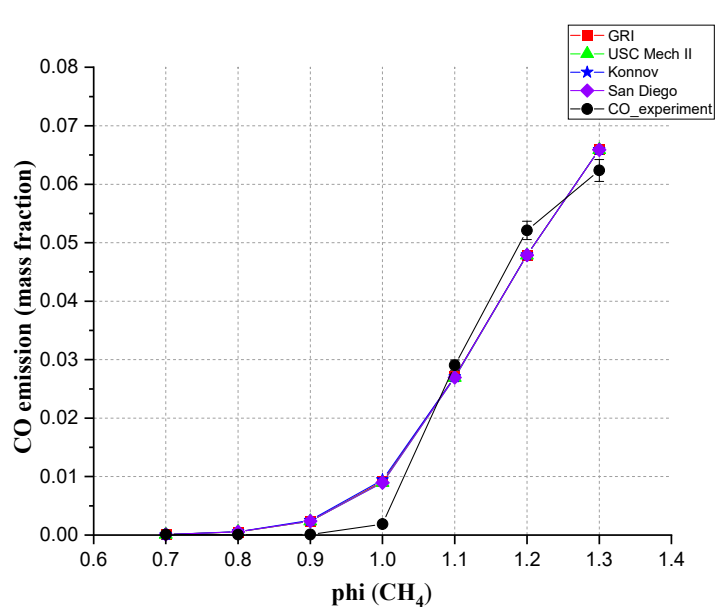

(a)

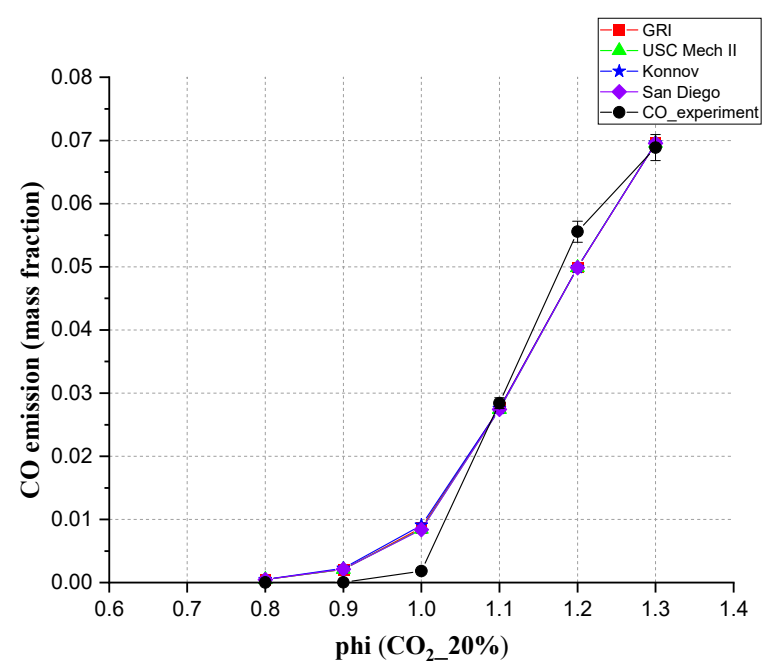

(b)

Figure 8. Cont. 


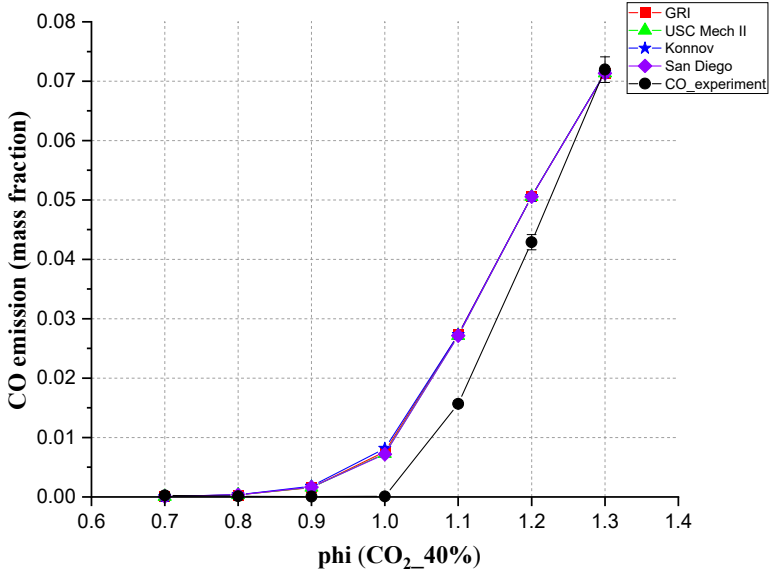

(c)

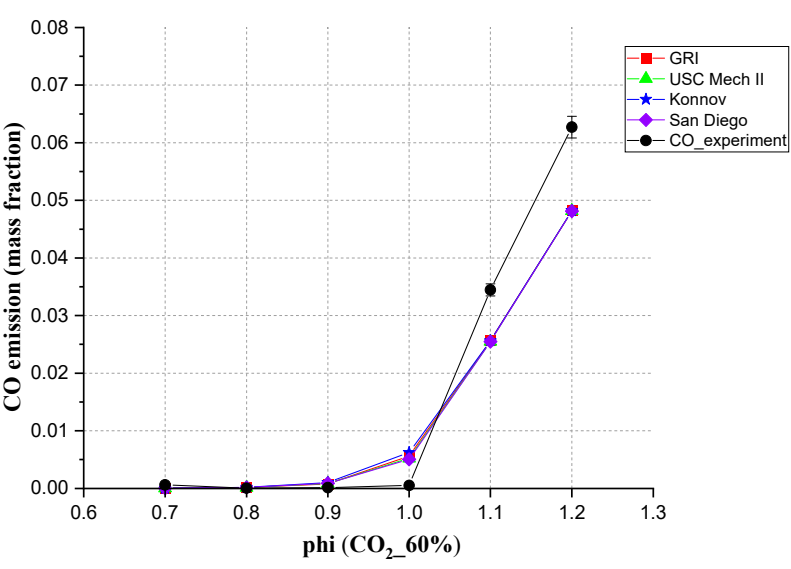

(d)

Figure 8. Comparison between simulation values (different simulation mechanisms at $20 \mathrm{~cm}$ downstream position) and experimental values for the mixed gas at (a) $\mathrm{CH}_{4}$, (b) $20 \% \mathrm{CO}_{2}$, (c) $40 \% \mathrm{CO}_{2}$, (d) $60 \% \mathrm{CO}_{2}$.

Figure 9 showed how $\mathrm{CO}_{2}$ concentrations affected $\mathrm{CO}$ emission from the perspectives of simulation and experiments. From the Chem1D simulation, adding $\mathrm{CO}_{2}$ to $\mathrm{CH}_{4}$ will produce more exhaust $\mathrm{CO}$ emissions when the $\mathrm{CO}_{2}$ ratio is between $0-40 \%$ in rich conditions. Between 40 to $60 \%$, the $\mathrm{CO}$ emission amount will decrease when more $\mathrm{CO}_{2}$ is added at these equivalence ratios. From the experiment, adding $\mathrm{CO}_{2}$ to $\mathrm{CH}_{4}$ from 0 to $20 \%$, the emission of $\mathrm{CO}$ had a significant increase. From the simulation, when $\mathrm{CO}_{2}=40 \%$, the value of $\mathrm{CO}$ emission reached the highest. In the experiment, the highest value of emission appeared at the $\mathrm{CO}_{2}$ concentration of $60 \%$.

The conclusion can be drawn here that for the mixed gas, all four mechanisms in Chem1D can be used to predict $\mathrm{CO}$ exhaust amount, especially when $\mathrm{CO}_{2}$ accounts for less than $40 \%$. These four mechanisms all showed a small error compared with the experiments. In the mixed gas, the proportion of $\mathrm{CO}_{2}$ does affect $\mathrm{CO}$ emissions. But only when the $\mathrm{CO}_{2}$ ratio was less than $20 \%$, compared with the pure $\mathrm{CH}_{4}$ gas, the impact was big. When the $\mathrm{CO}_{2}$ ratio was more than $20 \%$, the proportion of $\mathrm{CO}_{2}$ did not affect $\mathrm{CO}$ emissions so much.

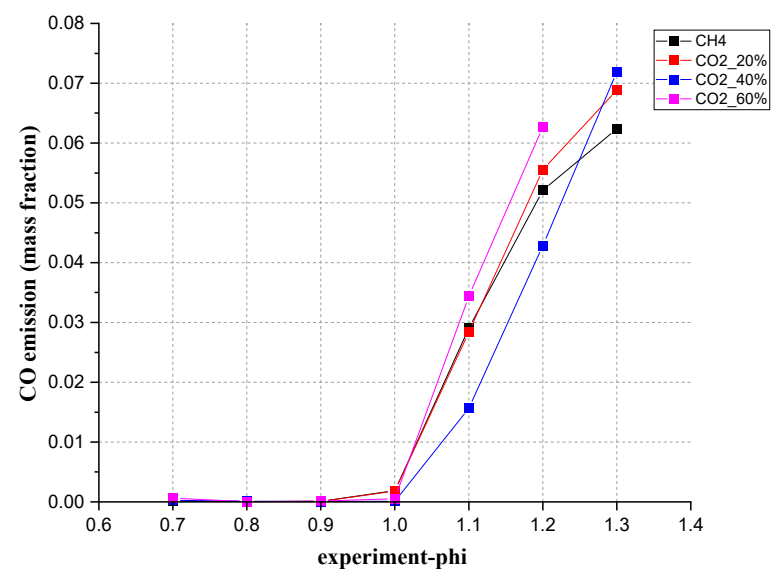

(a)

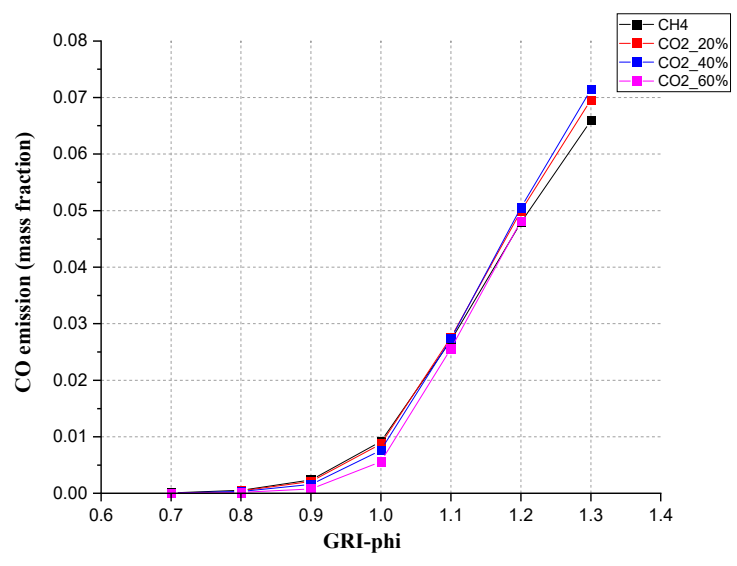

(b)

Figure 9. Cont. 


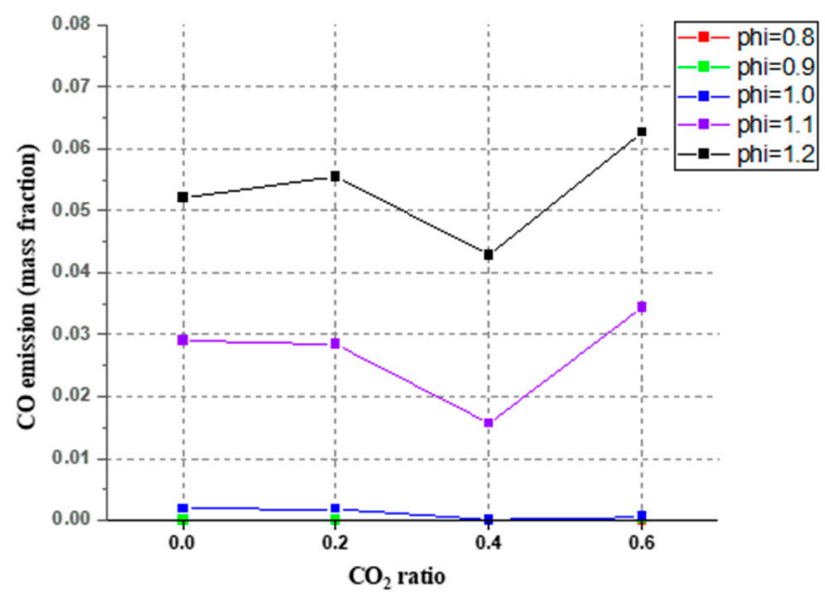

(c)

Figure 9. CO emission (a) measured, (b) simulated with GRI 3.0, (c) measured under different $\mathrm{CO}_{2}$ ratios.

\subsection{The Emission of NO between Simulation (20 cm Downstream Position) and Experimental Results}

The authors used three mechanisms to simulate NO emissions, which were GRI-Mech 3.0, Konnov, and San Diego. The USC Mech II mechanism programming does not involve the calculation of NO. From Figure 10, when the $\mathrm{CO}_{2}$ content was $40 \%$ and the $\Phi$ was between 0.7 to 1.2, the results from simulation (GRI-Mech 3.0) and experiment showed a good agreement. From the experimental results, the $\mathrm{NO}$ emission maintained a stable and low level, and showed a linear decreasing relationship as $\mathrm{CO}_{2}$ was added. All simulation results were higher than the experimental results. GRI 3.0 showed the smallest differences, therefore, GRI-Mech 3.0 was the best mechanism in this study to simulate NO emissions for mixed gases.

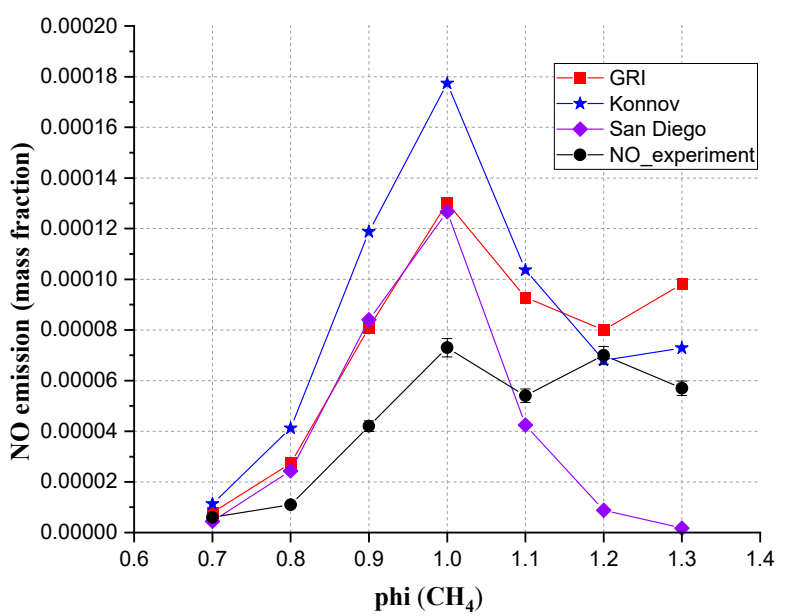

(a)

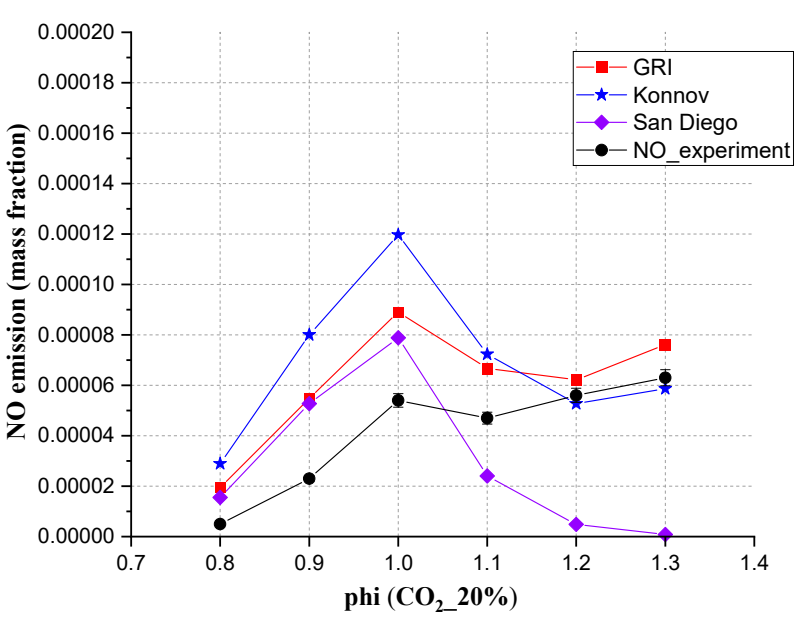

(b)

Figure 10. Cont. 


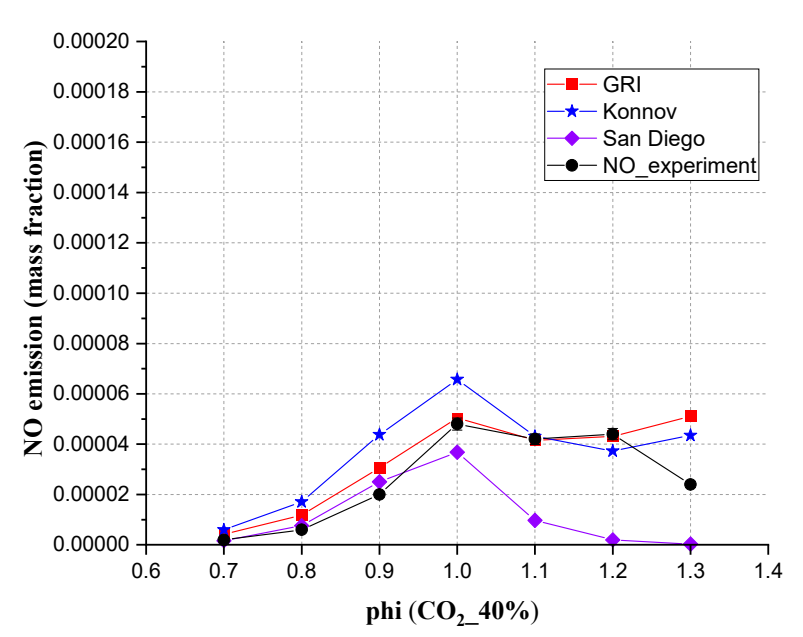

(c)

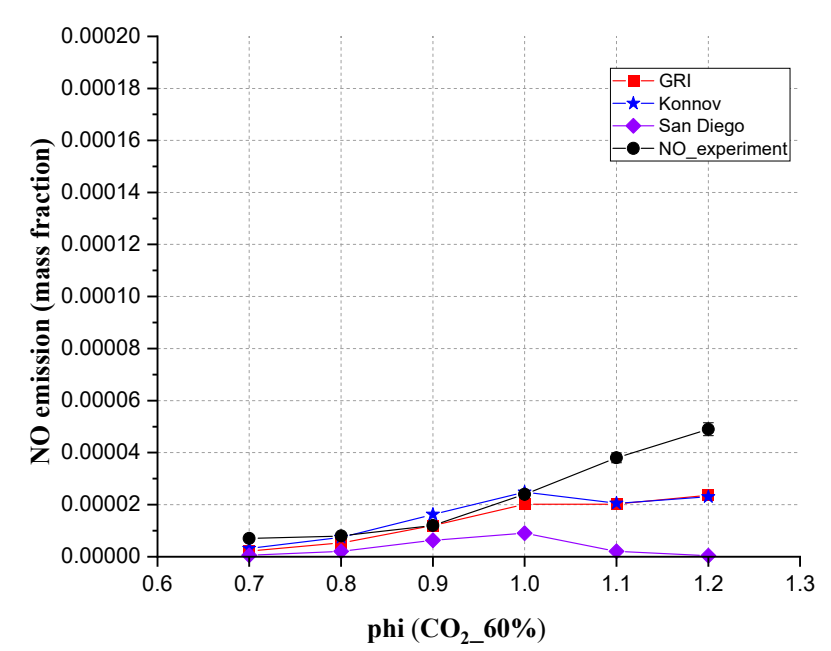

(d)

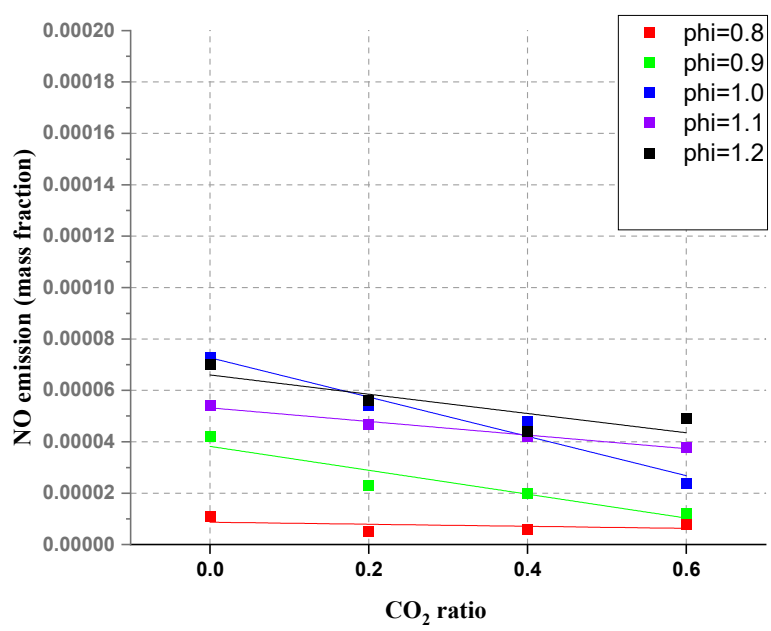

(e)

Figure 10. The comparison between simulation values (different simulation mechanisms) and experimental values for the mixed gas under every $\mathrm{CO}_{2}$ ratio at $20 \mathrm{~cm}$ downstream, (a) $\mathrm{CH}_{4}$, (b) $20 \%$ $\mathrm{CO}_{2}$, (c) $40 \% \mathrm{CO}_{2}$, (d) $60 \% \mathrm{CO}_{2}$. (e) The $\mathrm{NO}$ emission measured under different $\mathrm{CO}_{2}$ ratios.

From the simulation results of GRI Mech 3.0 in Figure 11b, the NO emission showed a proportional decline with the proportional addition of $\mathrm{CO}_{2}$. Of course, as an inert $\mathrm{CO}_{2}$ only lowers the temperature and reduces the Zeldovich effect. The experiment results from Figure 11a did not show a similar proportional decline but still showed a reduction tendency. When the equivalence ratio was 1.0, the order of the NO mass fraction was contrary to the concentration of $\mathrm{CO}_{2}$, which means the $\mathrm{CO}_{2}$ content affected the $\mathrm{NO}$ emission at $\Phi=1.0$. 


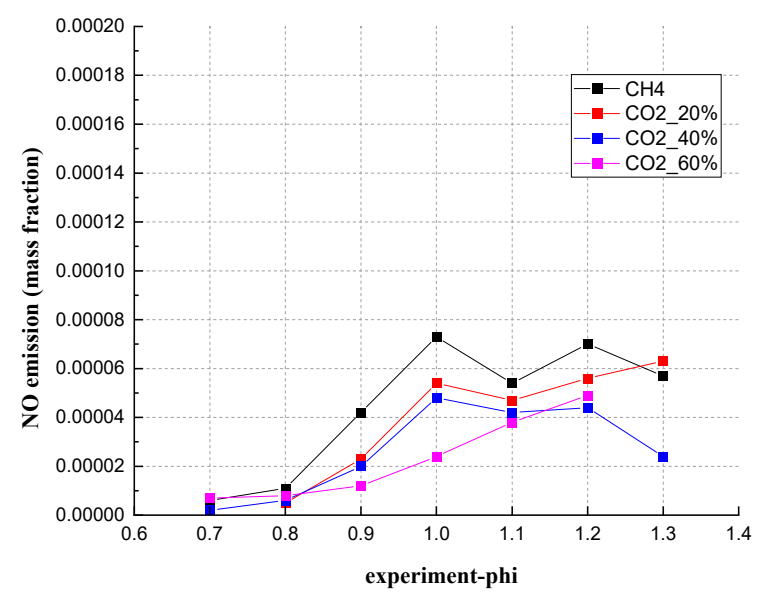

(a)

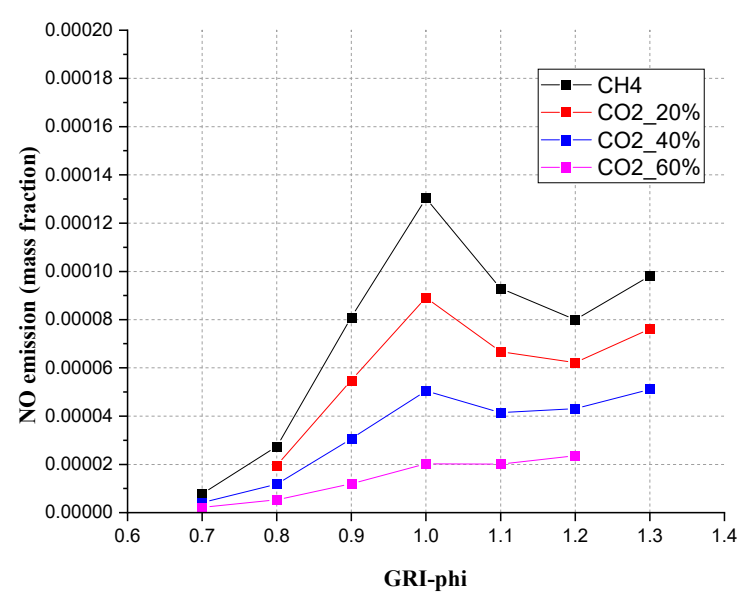

(b)

Figure 11. The $\mathrm{NO}$ emission of different $\mathrm{CO}_{2}$ compositions from (a) experiment, (b) simulated with GRI 3.0.

\subsection{Burning Velocities with Different Diffusion Methods}

Different diffusion approximations were used, complex, mixture averaged, constant Lewis numbers, and unity Lewis numbers. Of course, the complex and mixture averaged approximations showed the best agreement. The authors used the mixture averaged approach for burning velocity, $\mathrm{CO}$ emission, and $\mathrm{NO}$ emission in this research. The influence of the Lewis number on the numerical simulation results was studied in this chapter. A constant Lewis number approach is often used for analytical considerations. The setting of the Lewis number depends on the problem of concern. If the problem of concern is the thermal effect, the Lewis numbers are reasonable to be 1 , but if the focus is on the concentration of light molecules and their flame behavior, detailed complex diffusion must be used. This can explain why the constant Lewis number showed the worst agreement compared with other diffusion approximations. From Figure 12, for $\mathrm{CH}_{4}$, the curves from complex, mixture averaged, and unity Lewis numbers showed a very small deviation compared with the experiment results. For the mixture gas, like Figure $12 b$, when $\mathrm{CO}_{2}$ accounted for $20 \%$, there was a bigger deviation between the experimental results and simulation.

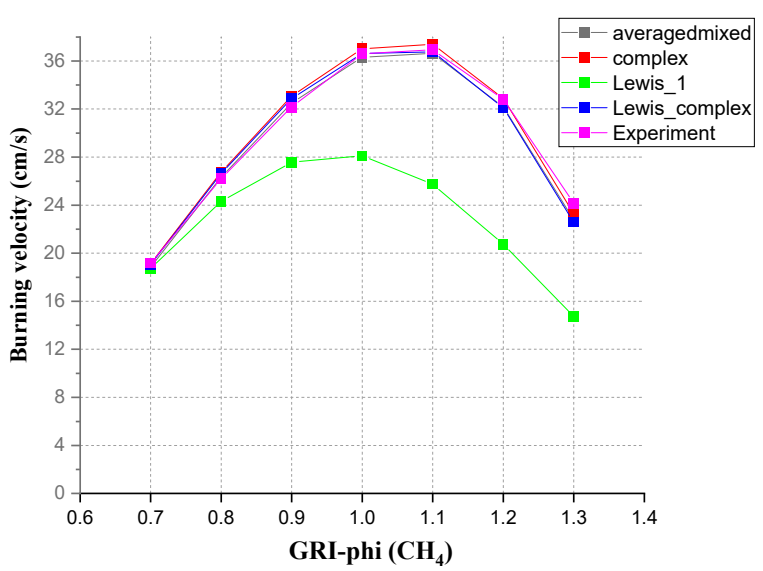

(a)

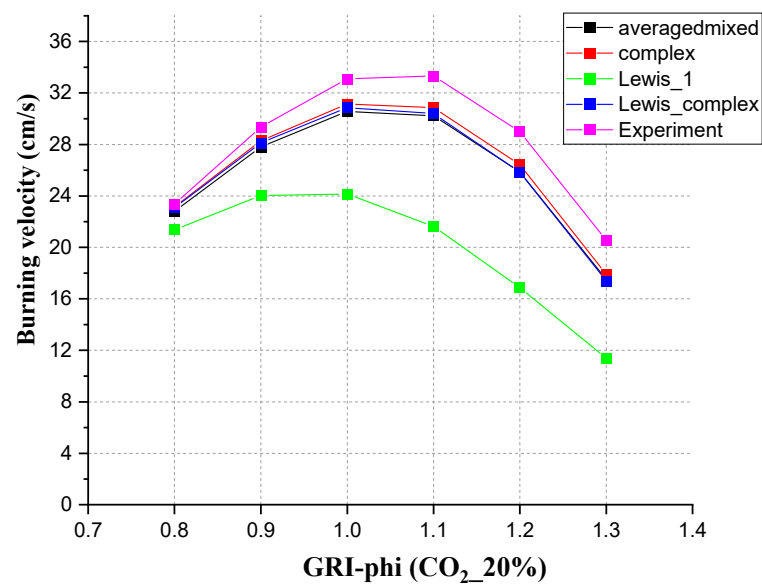

(b)

Figure 12. Burning velocities with different diffusion approaches using GRI 3.0 (a) for methane, (b) for the mixed gas. 


\section{Conclusions}

The experimental and numerical study of the laminar burning velocity and pollutant emissions of the mixture gas of methane and carbon dioxide were studied in this research. Compared with previous studies, a wider range of experimental conditions is realized in this paper: $\mathrm{CO}_{2}$ dilution level up to $60 \%$ and equivalence ratio of $0.7-1.3$. Furthermore, this research focused on the emissions of $\mathrm{CO}$ and $\mathrm{NO}$ after premixed combustion, which filled the gaps in other people's research. Depending on the results got in this research, the following conclusions can be given:

1. For laminar burning velocity simulation, four chemical kinetic mechanisms, GRIMech 3.0, San Diego, Konnov, and USC Mech II, all showed the same tendency compared with the experimental results. The simulation results were all lower than the experimental results. Consistent with the conclusion of Nonaka and Pereira [3], GRI Mech 3.0 showed the best agreement when the $\mathrm{CO}_{2}$ content was $20 \%$. USC Mech II showed the best consistency when the $\mathrm{CO}_{2}$ content was between $40 \%$ and $60 \%$. Agreement was limited when there were $\mathrm{CO}_{2}$ additions. The burning velocity showed a liner decrease while adding $\mathrm{CO}_{2}$.

2. For the $\mathrm{CO}$ emission, for the mixed gas, all four mechanisms in Chem1D can be used to predict $\mathrm{CO}$ exhaust amount. These four mechanisms all showed a small error compared with the experiments. When $\mathrm{CO}_{2}$ content was higher than $40 \%$, the deviation between simulation and experiment became bigger. In the mixed gas, the proportion of $\mathrm{CO}_{2}$ did affect $\mathrm{CO}$ emissions, making the $\mathrm{CO}$ emissions decrease first and then increase.

3. For the $\mathrm{NO}$ emission, when the $\mathrm{CO}_{2}$ content was $40 \%$, compared with the experimental results, the Chem1D can predict the mixed gas $\mathrm{NO}$ emission interval range. The NO emissions showed a linear relationship with the addition of $\mathrm{CO}_{2}$. In rich conditions, no matter how much $\mathrm{CO}_{2}$ accounted for, the $\mathrm{NO}$ emissions were all below 0.0001 mass fraction.

4. All in all, numerical simulation is a good way to predict burning velocities and $\mathrm{CO}$ emissions for 1D adiabatic flames. GRI Mech 3.0 is the best kinetic mechanism for this with the current mixtures. Adding $\mathrm{CO}_{2}$ to $\mathrm{CH}_{4}$ decreases the burning velocity but also decreases $\mathrm{NO}$ emissions and does not produce more $\mathrm{CO}$ emissions.

5. Different diffusion approximations were used, complex, mixture averaged, constant Lewis numbers, and unity Lewis numbers. Of course, the complex and mixture averaged approximations showed the best agreement. For $\mathrm{CH}_{4}$, the curves from complex, mixture averaged, and unity Lewis numbers showed a very small deviation compared with the experiment results. Different burning velocity approximations cause different burning rates estimations and, therefore, different $\mathrm{CO}$ and NOx emission rates. The exact impact should be investigated in an upcoming survey. For now, we can say that for truth-finding, complex diffusion is advised for use.

6. The authors found the mixed ratio for $\mathrm{CO}_{2}$ as $40 \%$ was a good balance between $\mathrm{S}_{\mathrm{L}}$ and pollutant emissions. For $\mathrm{S}_{\mathrm{L}}$, the curve from $\mathrm{CO}_{2}=40 \%$ did not show a big difference compared with $\mathrm{CH}_{4}$ but had a much lower $\mathrm{CO}$ and $\mathrm{NO}$ emission specifically at the point of $\Phi=1.0$. This is due to the inert dilution that lowers the product's temperature and, therefore, the thermal (Zeldovich) mechanism; thus, adding $\mathrm{CO}_{2}$ into $\mathrm{CH}_{4}$ is a good $\mathrm{NO}_{\mathrm{x}}$ removal method due to its low cost. Good advice can be provided here for industrial utilization by using $40 \% \mathrm{CO}_{2}$ of the natural gas, which can reduce the pollutant emission without drastically reducing the burning velocity. More simulation work to research the ignition delay time, chemical and thermal effects on burning velocity will be undertaken in the future. 


\begin{abstract}
Author Contributions: Conceptualization, Y.W. (Yalin Wang); methodology, Y.W. (Yalin Wang), R.J.M.B.; software, Y.W. (Yalin Wang), Y.W. (Yu Wang), R.J.M.B.; validation, Y.W. (Yalin Wang), Y.W. (Yu Wang), R.J.M.B.; formal analysis, Y.W. (Yalin Wang); investigation, Y.W. (Yalin Wang), R.J.M.B.; resources, Y.W. (Yalin Wang), R.J.M.B.; data curation, Y.W. (Yalin Wang).; writing-original draft preparation, Y.W. (Yalin Wang); writing-review and editing, Y.W. (Yalin Wang), R.J.M.B., Y.W. (Yu Wang), B.Y.; visualization, Y.W. (Yalin Wang), Y.W. (Yu Wang); supervision, B.Y., R.J.M.B.; project administration, G.Z., X.Z.; funding acquisition, G.Z., B.Y., R.J.M.B. All authors have read and agreed to the published version of the manuscript.
\end{abstract}

Funding: This research was financially supported by the China Scholarship Council (CSC) (201906250101), and the National Key Research and Development Program of China (2019YFD1100305).

Institutional Review Board Statement: Not applicable.

Informed Consent Statement: Not applicable.

Conflicts of Interest: The authors declare no conflict of interest.

\title{
References
}

1. Rasi, S.; Veijanen, A.; Rintala, J. Trace Compounds of Biogas from Different Biogas Production Plants. Energy 2007, 32, 1375-1380. [CrossRef]

2. Jönsson, O.; Polman, E.; Jensen, J.K.; Eklund, R.; Schyl, H.; Ivarsson, S. Sustainable Gas Enters the European Gas Distribution System; Danish Gas Technology Center: Copenhagen, Denmark, 2003; pp. 1-9.

3. Nonaka, H.O.B.; Pereira, F.M. Experimental and Numerical Study of $\mathrm{CO}_{2}$ Content Effects on the Laminar Burning Velocity of Biogas. Fuel 2016, 182, 382-390. [CrossRef]

4. Goswami, M.; Van Griensven, J.G.H.; Bastiaans, R.J.M.; Konnov, A.A.; De Goey, L.P.H. Experimental and Modeling Study of the Effect of Elevated Pressure on Lean High-Hydrogen Syngas Flames. Proc. Combust. Inst. 2015, 35, 655-662. [CrossRef]

5. Andrews, G.E.; Bradley, D. Determination of Burning Velocities: A Critical Review. Combust. Flame 1972, 18, 133-153. [CrossRef]

6. Zhao, P.; Yuan, W.; Sun, H.; Li, Y.; Kelley, A.P.; Zheng, X.; Law, C.K. Laminar Flame Speeds, Counterflow Ignition, and Kinetic Modeling of the Butene Isomers. Proc. Combust. Inst. 2015, 35, 309-316. [CrossRef]

7. de GOEY, L.P.H.; van MAAREN, A.; QUAX, R.M. Stabilization of Adiabatic Premixed Laminar Flames on a Flat Flame Burner. Combust. Sci. Technol. 1993, 92, 201-207. [CrossRef]

8. Rallis, C.J.; Garforth, A.M. The Determination of Laminar Burning Velocity. Prog. Energy Combust. Sci. 1980, 6, 303-329. [CrossRef]

9. Cohe, C.; Chauveau, C.; Gökalp, I.; Kurtuluş, D.F. $\mathrm{CO}_{2}$ Addition and Pressure Effects on Laminar and Turbulent Lean Premixed $\mathrm{CH}_{4}$ Air Flames. Proc. Combust. Inst. 2009, 32, 1803-1810. [CrossRef]

10. Galmiche, B.; Halter, F.; Foucher, F.; Dagaut, P. Effects of Dilution on Laminar Burning Velocity of Premixed Methane/Air Flames. Energy Fuels 2011, 25, 948-954. [CrossRef]

11. Halter, F.; Foucher, F.; Landry, L.; Mounaïm-Rousselle, C. Effect of Dilution by Nitrogen and/or Carbon Dioxide on Methane and Iso-Octane Air Flames. Combust. Sci. Technol. 2009, 181, 813-827. [CrossRef]

12. Xie, Y.; Wang, J.; Zhang, M.; Gong, J.; Jin, W.; Huang, Z. Experimental and Numerical Study on Laminar Flame Characteristics of Methane Oxy-Fuel Mixtures Highly Diluted with $\mathrm{CO}_{2}$. Energy Fuels 2013, 27, 6231-6237. [CrossRef]

13. Chen, Z.; Tang, C.; Fu, J.; Jiang, X.; Li, Q.; Wei, L.; Huang, Z. Experimental and Numerical Investigation on Diluted DME Flames: Thermal and Chemical Kinetic Effects on Laminar Flame Speeds. Fuel 2012, 102, 567-573. [CrossRef]

14. Qiao, L.; Dahm, W.; Faeth, G.; Oran, E. Burning Velocities and Flammability Limits of Premixed Methane/Air/Diluent Flames in Microgravity. In Proceedings of the 46th AIAA Aerospace Sciences Meeting and Exhibit, Reno, NV, USA, 7-10 January 2008; p. 959.

15. Van Maaren, A.; Thung, D.S.; DE GOEY, L.R.H. Measurement of Flame Temperature and Adiabatic Burning Velocity of Methane/Air Mixtures. Combust. Sci. Technol. 1994, 96, 327-344. [CrossRef]

16. Hermanns, R.T.E.; Kortendijk, J.A.; Bastiaans, R.J.M.; De Goey, L.P.H. Laminar Burning Velocities of Methane-Hydrogen-Air Mixtures. Ph.D. Thesis, Eindhoven University of Technology, Eindhoven, The Netherlands, 2007.

17. Dyakov, I.V.; Konnov, A.A.; Ruyck, J.D.; Bosschaart, K.J.; Brock, E.C.M.; De Goey, L.P.H. Measurement of Adiabatic Burning Velocity in Methane-Oxygen-Nitrogen Mixtures. Combust. Sci. Technol. 2001, 172, 81-96. [CrossRef]

18. Konnov, A.A.; Dyakov, I.V. Measurement of Propagation Speeds in Adiabatic Flat and Cellular Premixed Flames of $\mathrm{C}_{2} \mathrm{H}_{6}+\mathrm{O}_{2}+$ $\mathrm{CO}_{2}$. Combust. Flame 2004, 136, 371-376. [CrossRef]

19. Konnov, A.A.; Dyakov, I.V. Measurement of Propagation Speeds in Adiabatic Cellular Premixed Flames of $\mathrm{CH}_{4}+\mathrm{O}_{2}+\mathrm{CO}_{2} . E x p$. Therm. Fluid Sci. 2005, 29, 901-907. [CrossRef]

20. Coppens, F.H.V.; De Ruyck, J.; Konnov, A.A. Effects of Hydrogen Enrichment on Adiabatic Burning Velocity and NO Formation in Methane+ Air Flames. Exp. Therm. Fluid Sci. 2007, 31, 437-444. [CrossRef]

21. Clarke, A.; Stone, R.; Beckwith, P. Measuring the Laminar Burning Velocity of Methane/Diluent/Air Mixtures within a ConstantVolume Combustion Bomb in a Micro-Gravity Environment. Fuel Energy Abstr. 1995, 68, 130-136.

22. Skalska, K.; Miller, J.S.; Ledakowicz, S. Trends in NOx Abatement: A Review. Sci. Total Environ. 2010, 408, 3976-3989. [CrossRef] 
23. Abbasfard, H.; Hashemi, S.H.; Rahimpour, M.R.; Jokar, S.M.; Ghader, S. Reducing NO x Emissions from a Nitric Acid Plant of Domestic Petrochemical Complex: Enhanced Conversion in Conventional Radial-Flow Reactor of Selective Catalytic Reduction Process. Environ. Technol. 2013, 34, 2867-2879. [CrossRef]

24. Somers, L.B. The Simulation of Flat Flames with Detailed and Reduced Chemical Models. Ph.D. Thesis, Technische Universiteit Eindhoven, Eindhoven, The Netherlands, 1994.

25. Smith, G.P.; Golden, D.M.; Frenklach, M.; Moriarty, N.W.; Eiteneer, B.; Goldenberg, M.; Bowman, C.T.; Hanson, R.K.; Song, S.; Gardiner, W., Jr.; et al. Gri-Mech 3.0; Gas Research Institute: Chicago, IL, USA, 1999.

26. William, F.A.; Kalyanasundaram, S.; Cattolica, R.J. The San Diego Mechanism-Chemical-Kinetic Mechanisms for Combustion Applications; Mechanical and Aerospace Engineering (Combustion Research), University of California at San Diego: San Diego, CA, USA, 2012.

27. Konnov, A. Detailed Reaction Mechanism for Small Hydrocarbons Combustion, Release 0.4. 1998. Available online: http: //homepages.vub.ac.be/ \{\}akonnov/ (accessed on 10 January 2022).

28. Wang, H.; You, X.; Joshi, A.V.; Davis, S.G.; Laskin, A.; Egolfopoulos, F.; Law, C.K. USC Mech Version II. High-Temperature Combustion Reaction Model of $\mathrm{H}_{2} / \mathrm{CO} / \mathrm{C} 1-\mathrm{C} 4$ Compounds; Combustion Kinetics Laboratory, University of Southern California: Los Angeles, CA, USA, 2007.

29. Hinton, N.; Stone, R. Laminar Burning Velocity Measurements of Methane and Carbon Dioxide Mixtures (Biogas) over Wide Ranging Temperatures and Pressures. Fuel 2014, 116, 743-750. [CrossRef]

30. Powling, J. A New Burner Method for the Determination of Low Burning Velocities and Limits of Inflammability. Fuel 1949, 28, 25-28.

31. Bosschaart, K.J.; De Goey, L.P.H. Detailed Analysis of the Heat Flux Method for Measuring Burning Velocities. Combust. Flame 2003, 132, 170-180. [CrossRef]

32. Raida, M.B.; Hoetmer, G.J.; Konnov, A.A.; van Oijen, J.A.; de Goey, L.P.H. Laminar Burning Velocity Measurements of Ethanol+air and Methanol+air Flames at Atmospheric and Elevated Pressures Using a New Heat Flux Setup. Combust. Flame 2021, 230, 111435. [CrossRef]

33. Alekseev, V.A.; Naucler, J.D.; Christensen, M.; Nilsson, E.J.K.; Volkov, E.N.; de Goey, L.P.H.; Konnov, A.A. Experimental Uncertainties of the Heat Flux Method for Measuring Burning Velocities. Combust. Sci. Technol. 2016, 188, 853-894. [CrossRef]

34. Burcat, A.; Ruscic, B. Third Millenium Ideal Gas and Condensed Phase Thermochemical Database for Combustion (with Update from Active Thermochemical Tables); Argonne National Lab.: Argonne, IL, USA, 2005.

35. Li, J.; Zhao, Z.; Kazakov, A.; Chaos, M.; Dryer, F.L.; Scire, J.J., Jr. A Comprehensive Kinetic Mechanism for $\mathrm{CO} \mathrm{CH}_{2} \mathrm{O}$, and $\mathrm{CH}_{3} \mathrm{OH}$ Combustion. Int. J. Chem. Kinet. 2007, 39, 109-136. [CrossRef]

36. Burke, M.P.; Chaos, M.; Ju, Y.; Dryer, F.L.; Klippenstein, S.J. Comprehensive $\mathrm{H}_{2} / \mathrm{O}_{2}$ Kinetic Model for High-Pressure Combustion. Int. J. Chem. Kinet. 2012, 44, 444-474. [CrossRef]

37. Kéromnès, A.; Metcalfe, W.K.; Heufer, K.A.; Donohoe, N.; Das, A.K.; Sung, C.-J.; Herzler, J.; Naumann, C.; Griebel, P.; Mathieu, O.; et al. An Experimental and Detailed Chemical Kinetic Modeling Study of Hydrogen and Syngas Mixture Oxidation at Elevated Pressures. Combust. Flame 2013, 160, 995-1011. [CrossRef]

38. Bosschaart, K.J.; Versluis, M.; Knikker, R.; Vandermeer, T.H.; Schreel, K.; De Goey, L.P.H.; Van Steenhoven, A.A. The Heat Flux Method for Producing Burner Stabilized Adiabatic Flames: An Evaluation with CARS Thermometry. Combust. Sci. Technol. 2001, 169, 69-87. [CrossRef]

39. Hermanns, R.T.E.; Konnov, A.A.; Bastiaans, R.J.M.; de Goey, L.P.H.; Lucka, K.; Köhne, H. Effects of Temperature and Composition on the Laminar Burning Velocity of $\mathrm{CH}_{4}+\mathrm{H}_{2}+\mathrm{O}_{2}+\mathrm{N}_{2}$ Flames. Fuel 2010, 89, 114-121. [CrossRef]

40. Goswami, M.; Derks, S.C.R.; Coumans, K.; Slikker, W.J.; de Andrade Oliveira, M.H.; Bastiaans, R.J.M.; Luijten, C.C.M.; de Goey, L.P.H.; Konnov, A.A. The Effect of Elevated Pressures on the Laminar Burning Velocity of Methane+air Mixtures. Combust. Flame 2013, 160, 1627-1635. [CrossRef]

41. He, Y.; Wang, Z.; Weng, W.; Zhu, Y.; Zhou, J.; Cen, K. Effects of CO Content on Laminar Burning Velocity of Typical Syngas by Heat Flux Method and Kinetic Modeling. Int. J. Hydrog. Energy 2014, 39, 9534-9544. [CrossRef]

42. Zahedi, P.; Yousefi, K. Effects of Pressure and Carbon Dioxide, Hydrogen and Nitrogen Concentration on Laminar Burning Velocities and NO Formation of Methane-Air Mixtures. J. Mech. Sci. Technol. 2014, 28, 377-386. [CrossRef] 